\title{
An UFLC-DAD Method for the Quantification of Menaquinone-4 in Spiked Rabbit Plasma
}

\author{
Karthika Anoop', Gullapalli Kowmudi', Mukkamala Sailaja', Krishna Veni Nagappan ${ }^{1,}$, Nagarajan Janaki Sankarachari Krishnan ${ }^{1}$, \\ Ramalingam Peraman² \\ 'Department of Pharmaceutical Analysis JSS College of Pharmacy, Ooty [A Constituent College - JSS Academy of Higher Education \& Research], Rocklands, Ooty, Tamil \\ Nadu, INDIA. \\ 2Department of Medical Chemistry, Raghavendra Institute of Pharmaceutical Education and Research, Chiyyedu, Anantapur, Andhra Pradesh, INDIA.
}

\begin{abstract}
Objective: The present study is aimed to develop and validate an Ultra-Fast Liquid Chromatography-Diode Array Detector (UFLC-DAD) method for the quantification of vitamin K2 as Menaquinone-4 (MK-4) in rabbit plasma. Method: Standard solutions and spiked plasma samples of MK-4 and Internal Standard (IS) were prepared from primary stock solutions of 1mg/ $\mathrm{ml}$ concentration in ethanol each. Protein precipitation was carried out for the MK-4 and IS extraction from plasma spiked samples. Chromatographic separation was employed using Isopropyl Alcohol and Acetonitrile (50:50 $\mathrm{v} / \mathrm{v}$ ) as mobile phase and a C-18 column with $1 \mathrm{ml} / \mathrm{min}$ flow rate and a run time of 10 mins. Detection was carried out in the range 190-600 nm with $269 \mathrm{~nm}$ set as a reference wavelength. Result: The retention times of MK-4 and IS were at $5.5 \pm 0.5$ mins and $8 \pm 0.5$ mins respectively. Calibration curve for MK-4 was found to be linear in the range of 0.374 to $6 \mu \mathrm{g} /$ $\mathrm{ml}$ with an $R^{2}$ value of 0.9934 . The $\%$ RSD for accuracy was $<15 \%$, inter
\end{abstract}

and intraday precisions were $<10 \%$. The samples were found to be stable throughout the study. Conclusion: This method can be applied to the estimation of MK-4 in rabbit plasma using UFLC-DAD.

Key words: Bioanalytical method, Ultra-Fast Liquid Chromatography (UFLCDAD), Menaquinone-4, Rabbit plasma, Validation.

Correspondence

Dr. Krishna Veni Nagappan, Department of Pharmaceutical Analysis JSS College of Pharmacy, Ooty [A Constituent College - JSS Academy of Higher Education \& Research], Rocklands, Ooty, Tamil Nadu, INDIA.

Phone: +91-423-2443393/231

Email: krisath@jssuni.edu.in

DOI: 10.5530/jyp.2019.11.32

\section{INTRODUCTION}

There is expanding enthusiasm for the potential medical advantages of vitamin $\mathrm{K}$ past its part in coagulation. A few examinations have announced capacities for vitamin $\mathrm{K}$ past its established part, including the change of bone health, ${ }^{1}$ also, the diminishment of vascular calcification and cardiovascular risk..$^{2,3}$ Besides, a few studies ${ }^{2-4}$ have proposed that menaquinones, otherwise called vitamin $\mathrm{K}_{2}$, could be more potent in these capacities than Phylloquinone, otherwise called vitamin $\mathrm{K}_{1}$.

Menaquinones, generally found in nature, have side chains of fluctuating length in the vicinity of four and thirteen isoprene units, the vast majority of which are unsaturated. ${ }^{5} \mathrm{MK}-4$ is extraordinary among the menaquinones in that microscopic organisms do not orchestrate it. Instead, MK-4 is alkylated from menadione (Vitamin $\mathrm{K}_{3}$ ), a manufactured type of vitamin $\mathrm{K}$ that is available in animal feeds or is the result of tissuespecific transformation specifically from dietary phylloquinone, with menadione as the hypothesized intermediate. ${ }^{6,7}$ There is additionally a theory that more extended chain menaquinones, for example, MK-7, can be changed over to MK-4 as well. ${ }^{8}$ The most bounteous menaquinones in the human eating regimen are the short chain MK-4, originates from animal products and the long-chain MK-7, MK-8, MK-9 and MK-10.

All types of vitamin $\mathrm{K}$ have one open capacity. They are all filled in as a cofactor for the post-translational enzyme gamma-glutamyl carboxylase, which is set up by the basic naphthoquinone ring structure. ${ }^{9}$ This catalyst changes over particular protein-bound glutamate deposits into gamma-carboxyglutamate, by and large, known as Gla. Presently, seventeen individuals from the Gla protein family are known, incorporating seven proteins associated with blood coagulation (All combined in the liver), Osteocalcin (OC; bone), Matrix Gla Protein (MGP; for the most part ligament and vessel wall), growth arrest-specific protein 6, Gla-rich proteins, periostin and periostin-like factor. ${ }^{10}$ Aside from the thickening elements OC (Bone arrangement) and MGP (Inhibitor of delicate tissue calcification), the physiological significance of these proteins is not yet completely understood. ${ }^{10}$ Amidst all the above benign effects of menaquinone- 4 , the necessity to develop a simple, accurate and reliable method for analysis of menaquinone- 4 in biological samples is essential and also is the aim of our study.

\section{MATERIALS AND METHODS}

\section{Chemicals and reagents Reference standards}

Vitamin $\mathrm{K}_{2}$ (Menaquinone-4) was purchased from Sigma Aldrich, (Bangalore) India and Vitamin $\mathrm{K}_{1}$ (IS) was purchased from SUPELCO, (Bellefonte) in the USA. The structures of these compounds are shown in Figures 1 and 2 respectively.

\section{Solvents}

HPLC Grade Solvent Acetonitrile was purchased from Merck, (Mumbai, India). Isopropyl alcohol AR grade was purchased from Qualigens fine chemicals (Mumbai, India). Milli-Q-water for HPLC analysis and extraction was obtained using a milli-Q-purification system (Millipore, Bedford, USA).

\section{Biological matrix}

Drug-free rabbit plasma was obtained from Centralized Animal House, Department of Pharmacology and Toxicology, JSS College of Pharmacy (Ooty, Tamil Nadu). 


\section{Chromatographic conditions}

Separation was performed using a Shimadzu gradient UFLC system (Shimadzu, Japan) equipped with a diode array detector. The separation was carried out on a reverse phase column SHIMPAC C ${ }_{18}(250 \mathrm{~mm} \times 4.6$ $\mathrm{mm}$ i.d, $5 \mu \mathrm{m}$ ). The column was operated at $23^{\circ} \mathrm{C}$ (Ambient temperature). The mobile phase was Isopropyl alcohol/Acetonitrile (50:50 v/v) with a flow rate of $1 \mathrm{ml} / \mathrm{min}$. Detection was carried out in the range 190-600 $\mathrm{nm}$ at $269 \mathrm{~nm}$ set as a reference wavelength. The injection volume of prepared samples were $20 \mu \mathrm{l}$. Lab solutions data station processed the chromatograms. The total runtime per injection was 10 mins. Solutions used were protected from light and maintained at $-20^{\circ} \mathrm{C}$ before analysis.

\section{Preparation of primary stock and working solutions}

A $1 \mathrm{mg} / \mathrm{ml}$ primary stocks of menaquinone-4 and vitamin $\mathrm{K}_{1}$ (Internal standard) in ethanol were prepared using certified standards. Working solutions with concentrations 100,10 and $1 \mu \mathrm{g} / \mathrm{ml}$ were prepared by appropriately diluting $1 \mathrm{mg} / \mathrm{ml}$ stock with ethanol.

\section{Preparation of calibration standards}

Calibration standards were prepared by serially diluting working solutions to achieve final concentrations of $0.374-6 \mu \mathrm{g} / \mathrm{ml}$. All internal standard spiked samples were prepared such that the final concentration of internal standard is $5 \mu \mathrm{g} / \mathrm{ml}$.

\section{Preparation of quality control samples}

Quality control samples were prepared in concentrations of $4.2 \mu \mathrm{g} / \mathrm{ml}$ (HQC), $1.73 \mu \mathrm{g} / \mathrm{ml}$ (MQC) and $0.85 \mu \mathrm{g} / \mathrm{ml}$ (LQC).

\section{Preparation of plasma samples}

Standards were prepared using plasma from the control group of healthy rabbits. Aliquots of plasma were spiked with known amounts of MK-4 and $\mathrm{K}_{1}$ standard stock solutions ranging from $14.96-240 \mu \mathrm{g} / \mathrm{ml}$ to obtain working standards ranging from $0.374-6 \mu \mathrm{g} / \mathrm{ml}$. A suitable dilution of the stock solution of IS was made and spiked to blank plasma to obtain a final concentration of $5 \mu \mathrm{g} / \mathrm{ml}$. The spiked plasma samples were stored at $-20^{\circ} \mathrm{C}$ until further analysis. Quality control samples were prepared by spiking the blank plasma samples to obtain $0.85 \mu \mathrm{g} / \mathrm{ml}$ (LQC), $1.73 \mu \mathrm{g} /$ $\mathrm{ml}$ (MQC) and $4.2 \mu \mathrm{g} / \mathrm{ml}$ (HQC). Menaquinone- 4 depleted plasma was prepared by exposing plasma to UV light over $2 \mathrm{hrs}$.

\section{Sample extraction}

Protein precipitation technique was employed for sample extraction. For determination, we used $1.8 \mathrm{ml}$ plasma (Control, calibrator); Sample of $50 \mu \mathrm{l}$ volume was mixed; $50 \mu \mathrm{l}$ of internal standard (Vitamin $\mathrm{K}_{1}$ ) and acetonitrile (100 $\mu \mathrm{l}$ as precipitating agent) were added. The mixture was vortexed for $3 \mathrm{mins}$ and then centrifuged at $5000 \mathrm{rpm}$ for $15 \mathrm{mins}$. The supernatant was collected for vortexing followed by centrifugation at $5000 \mathrm{rpm}$ for 15 mins. The resulting supernatant was subjected for further analysis in UFLC by taking aliquots of $20 \mu \mathrm{l}$ per injection.

We measured plasma samples from albino rabbits. All plasma samples were obtained in tubes with a clot activator (Vacuette, Germany) and the tubes were protected from light, centrifuged $15 \mathrm{mins}$ at $5000 \mathrm{rpm}$ and immediately stored at $-80^{\circ} \mathrm{C}$. The samples were stored for a maximum of three months before the analysis.

\section{Method validation}

Method validation procedures were performed concerning US FDA bioanalytical method validation guideline to evaluate the method suitability for the quantitative determination of menaquinone- 4 in rabbit plasma.

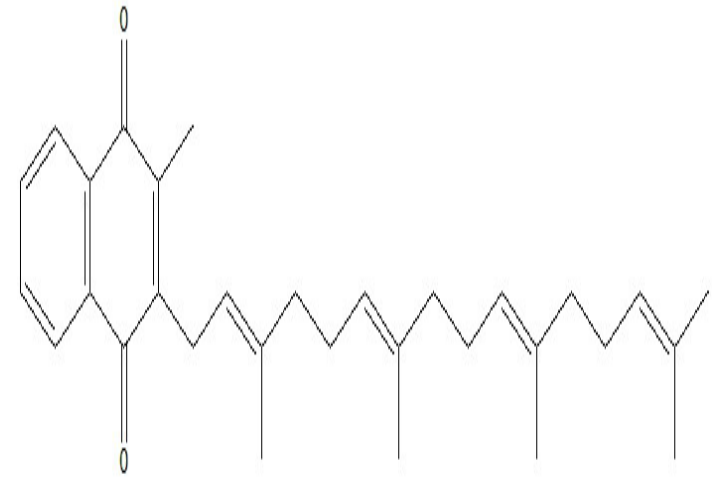

Figure 1: Structure of Menaquinone-4.

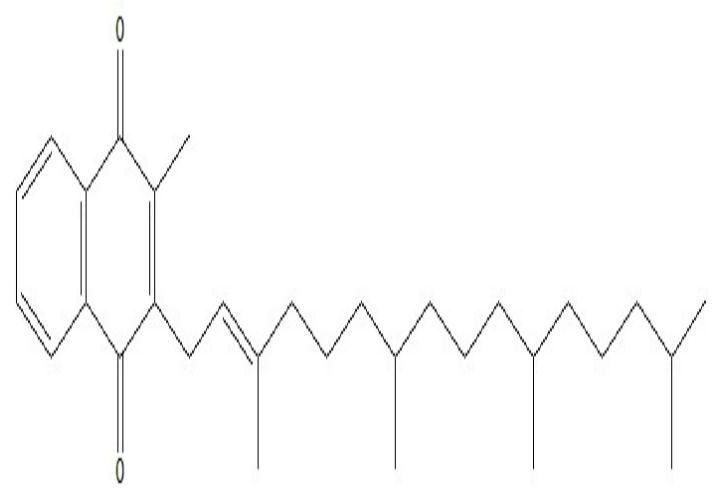

Figure 2: Structure of Vitamin K1 (Internal standard).

\section{Statistical analysis}

Statistical analysis was conducted and data reported as mean \pm S.D using MS Excel 2013 (Microsoft Corporation, USA).

\section{RESULTS}

\section{Method validation}

The real goal of the validation process is to challenge the method and to determine the limits of allowed variability for the conditions needed to run the method. The components of validation methods and procedure adopted for the method validation were presented earlier. This section deals with the discussions of the results obtained.

\section{Linearity}

It was observed that the optimized methods were linear within a specific concentration range for MK-4. The calibration curve was plotted between response factor and concentrations of the standard solution (Figure 3).

The linearity for menaquinone- 4 was performed for the spiked plasma at the following concentrations of $0.374,0.85,1.73,3,4.2,5.4$ and $6 \mu \mathrm{g} / \mathrm{ml}$. The $R^{2}$ value was found to be 0.9937 .

The calibration curves were constructed on six different days throughout one week to determine the variability of the slopes and intercepts. The results indicated that no significant inter-day variability of slopes and intercepts over the optimized concentration range. (Table 1)

\section{Accuracy and precision}

Relative and absolute recovery experiments determined the accuracy of the optimized method. The percentage recovery values for menaqui- 


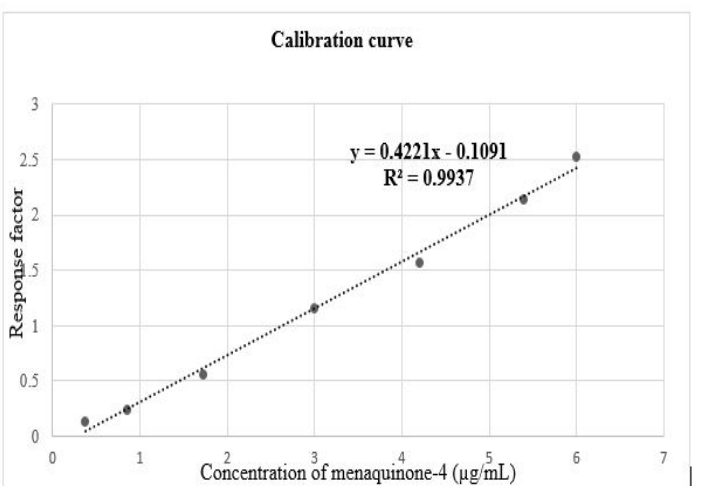

Figure 3: Calibration Curve of Concentration Range of 0.374 to $6 \mu \mathrm{g} / \mathrm{ml}$ in Spiked Rabbit Plasma.

\begin{tabular}{|c|c|c|c|c|}
\hline $\begin{array}{l}\text { S. } \\
\text { No }\end{array}$ & $\begin{array}{l}\text { Analyte Conc. ( } \mu \mathrm{g} / \\
\mathrm{ml} \text { ) } \\
\text { (menaquinone-4) }\end{array}$ & $\begin{array}{c}\text { Mean area } \\
\text { Observed }\end{array}$ & $\begin{array}{c}\text { Mean Internal } \\
\text { Standard area } \\
\text { observed (Conc } \\
2 \mu \mathrm{g} / \mathrm{ml})\end{array}$ & $\begin{array}{c}\text { Response } \\
\text { Factor }\end{array}$ \\
\hline 1 & 0.374 & 15994 & 115601 & 0.1383 \\
\hline 2 & 0.850 & 25851 & 113341 & 0.2338 \\
\hline 3 & 1.73 & 66975 & 118533 & 0.5651 \\
\hline 4 & 3 & 134328 & 115935 & 1.1587 \\
\hline 5 & 4.2 & 185810 & 118533 & 1.5707 \\
\hline 6 & 5.4 & 243220 & 114040 & 2.1364 \\
\hline 7 & 6 & 319849 & 121551 & 2.5316 \\
\hline
\end{tabular}

ranged from 90.6 to $94.4 \%$. It is, therefore, derived that the developed methods are accurate and reliable. The data is given in Table 2.

The optimized methods for the estimation of the drugs were found to be precise. This was evident from the coefficient of variation values, the observed \% CV for the developed method is between 3-5 \% indicating the developed method to be precise. The results are presented in Table 3.

The six blank plasma samples were analyzed and the chromatograms were recorded. Endogenous interferences were not detected at the retention time of selected drugs and internal standard. No additional peaks were observed in the sample chromatograms.

These peaks, however, did not interfere with the drugs and internal standard peaks. These observations show that the developed assay method is specific and selective and the chromatograms are shown in Figures 4, $5,6,7$ and 8 .

The Retention time of menaquinone- 4 is $5.5 \pm 0.5$ mins and Internal Standard Retention time was $8 \pm 0.5$ mins, therefore there was no interference between internal standard peak and drug peak.

\section{Stability}

Stability of the sample, standard and reagents used in an HPLC method is required for a reasonable time to generate reproducible and reliable results. Stability of plasma samples spiked with drugs for LQC, MQC and HQC samples were subjected to three freeze-thaw cycles, short-term stability at ambient temperature for $6 \mathrm{hrs}$ and bench top stability at $2-8^{\circ} \mathrm{C}$
Table 2: Recovery Studies of Menaquinone-4 from Spiked Rabbit Plasma ( $n=6)$.

\begin{tabular}{cccc}
\hline \multirow{2}{*}{$\begin{array}{c}\text { Concentration }(\mathrm{g} / \\
\mathrm{mL})\end{array}$} & \multicolumn{3}{c}{ Menaquinone-4 } \\
\cline { 2 - 4 } & $\begin{array}{c}\text { Mean }(\mu \mathrm{g} / \mathrm{mL}) \\
\pm \mathrm{SD}\end{array}$ & RSD (\%) & Recovery (\%) \\
\hline $0.85(\mathrm{LQC})$ & $0.773 \pm 0.005$ & 0.65 & 90.96 \\
$1.73(\mathrm{MQC})$ & $1.63 \pm 0.028$ & 1.73 & 94.24 \\
$4.2(\mathrm{HQC})$ & $3.96 \pm 0.018$ & 0.47 & 94.38 \\
\hline
\end{tabular}

Table 3: Precision Studies of Menaquinone-4 $(\mu \mathrm{g} / \mathrm{ml})(n=6)$ in Spiked Rabbit Plasma.

\begin{tabular}{|c|c|c|c|c|}
\hline \multirow[b]{2}{*}{ Analyte } & \multirow[b]{2}{*}{$\begin{array}{c}\mathrm{QCs}(\mu \mathrm{g} / \\
\mathrm{ml})\end{array}$} & \multirow{2}{*}{$\begin{array}{c}\text { Mean } \\
\text { concentration } \\
\text { found }(\mu \mathrm{g} / \mathrm{ml}) \\
+\mathrm{SD}\end{array}$} & \multicolumn{2}{|c|}{ Intra-day } \\
\hline & & & $\begin{array}{c}\text { Recovery } \\
\text { (\%) }\end{array}$ & $\begin{array}{c}\text { Precision } \\
\text { (\% RSD) }\end{array}$ \\
\hline \multirow[t]{3}{*}{ Menaquinone-4 } & $\begin{array}{c}\text { LQC } \\
(0.85)\end{array}$ & $0.078 \pm 0.049$ & 92.00 & 4.82 \\
\hline & $\begin{array}{l}\text { MQC } \\
(1.73)\end{array}$ & $1.636 \pm 0.03$ & 94.60 & 3.21 \\
\hline & $\begin{array}{c}\text { HQC } \\
(4.2)\end{array}$ & $3.98 \pm 0.02$ & 94.76 & 3.04 \\
\hline
\end{tabular}

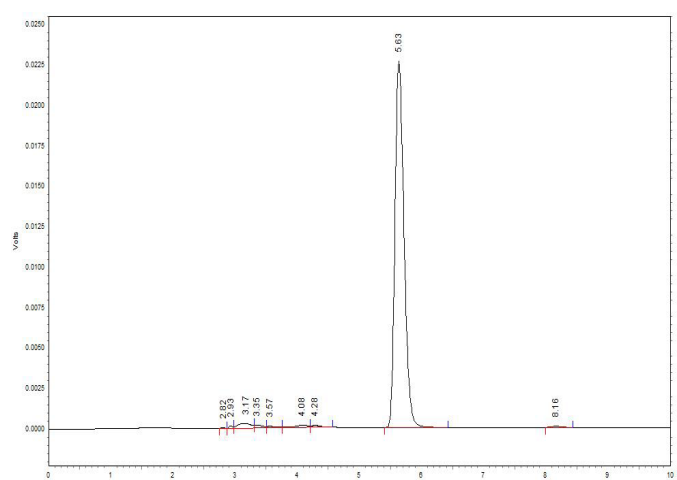

Figure 4: Chromatogram of Standard Menaquinone-4.

none- 4 in plasma ranged from 90.9 to $94.3 \%$ and in aqueous solution ranged from 90.6 to $94.4 \%$. It is, therefore, derived that the developed methods are accurate and reliable. The data is given in Table 2 .

The optimized methods for the estimation of the drugs were found to be precise. This was evident from the coefficient of variation values, the observed \% CV for the developed method is between 3-5 \% indicating the developed method to be precise. The results are presented in Table 3. The six blank plasma samples were analyzed and the chromatograms were recorded. Endogenous interferences were not detected at the retention time of selected drugs and internal standard. No additional peaks were observed in the sample chromatograms.

These peaks, however, did not interfere with the drugs and internal standard peaks. These observations show that the developed assay method is specific and selective and the chromatograms are shown in Figures 4, 5, 6, 7 and 8 .

The Retention time of menaquinone- 4 is $5.5 \pm 0.5 \mathrm{mins}$ and Internal Standard Retention time was $8 \pm 0.5$ mins, therefore there was no interference between internal standard peak and drug peak. 


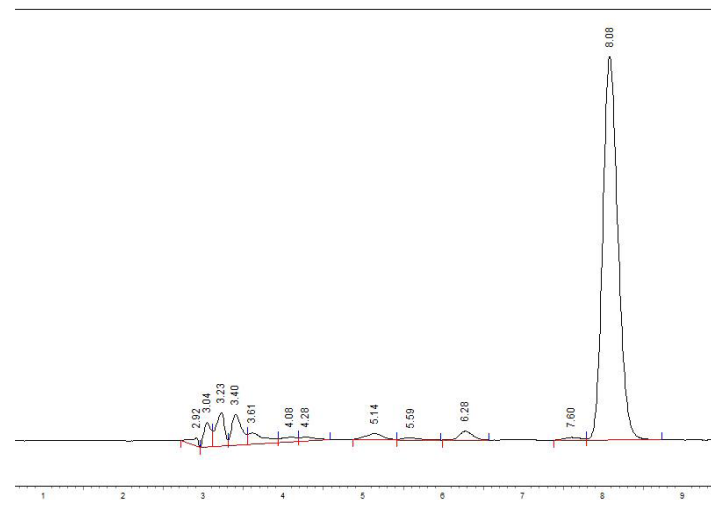

Figure 5: Chromatogram of Internal Standard (Vitamin K1).

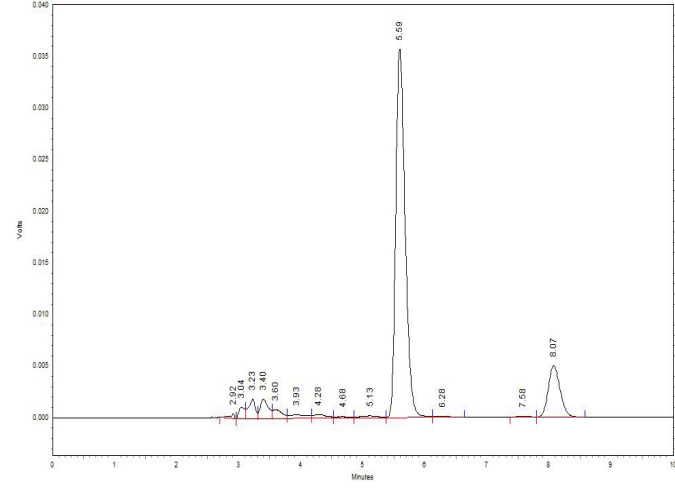

Figure 6: Chromatogram of Menaquinone-4 and IS Standard.

Table 4: Stability of Menaquinone-4 in Rabbit Plasma during Storage and Sample Handling.

\begin{tabular}{|c|c|c|c|c|}
\hline \multirow[t]{2}{*}{ Type of stability } & \multicolumn{4}{|c|}{ Menaquinone-4 } \\
\hline & S. No & LQC $(0.85 \mu \mathrm{g} / \mathrm{mL})$ & $\mathrm{MQC}(1.73 \mu \mathrm{g} / \mathrm{mL})$ & $\mathrm{HQC}(4.2 \mu \mathrm{g} / \mathrm{mL})$ \\
\hline \multirow{6}{*}{ Freeze and thaw } & 1. & 0.79 & 1.688 & 3.822 \\
\hline & 2. & 0.801 & 1.692 & 3.796 \\
\hline & 3. & 0.786 & 1.672 & 3.881 \\
\hline & Mean & 0.80675 & 1.6955 & 3.92475 \\
\hline & S.D $( \pm)$ & 0.009601 & 0.010379 & 0.058045 \\
\hline & C.V & 1.190104 & 0.612166 & 1.478939 \\
\hline \multirow{5}{*}{ Bench -Top } & 1. & 0.783 & 1.673 & 3.771 \\
\hline & 2. & 0.768 & 1.652 & 3.713 \\
\hline & 3. & 0.779 & 1.669 & 3.801 \\
\hline & Mean & 0.776667 & 1.664667 & 3.761667 \\
\hline & S.D $( \pm)$ & 0.006342 & 0.009104 & 0.036527 \\
\hline \multirow{7}{*}{ Short Term Stability } & C.V & 0.816579 & 0.546916 & 0.971033 \\
\hline & 1. & 0.797 & 1.669 & 3.782 \\
\hline & 2. & 0.768 & 1.653 & 3.801 \\
\hline & 3. & 0.78 & 1.621 & 3.659 \\
\hline & Mean & 0.781667 & 1.647667 & 3.747333 \\
\hline & S.D $( \pm)$ & 0.011898 & 0.019956 & 0.062941 \\
\hline & C.V & 1.522095 & 1.211137 & 1.679618 \\
\hline
\end{tabular}

\section{Stability}

Stability of the sample, standard and reagents used in an HPLC method is required for a reasonable time to generate reproducible and reliable results. Stability of plasma samples spiked with drugs for LQC, MQC and HQC samples were subjected to three freeze-thaw cycles, short-term stability at ambient temperature for $6 \mathrm{hrs}$ and bench top stability at $2-8^{\circ} \mathrm{C}$ for $8 \mathrm{hrs}$. The stability of these solutions was studied by performing the experiment and looking for changes in separation, retention and asymmetry of the peaks which were then compared with the pattern of the chromatogram of freshly prepared solutions. The stability data is shown in Table 4.

\section{Limit of detection and limit of quantification}

The Limit of Detection (LOD) values for menaquinone-4 was found to be $0.187 \mu \mathrm{g} / \mathrm{ml}$ and the Limit of Quantification (LOQ) value was 0.85 $\mu \mathrm{g} / \mathrm{ml}$. This observation in Table 5 showed that the developed methods have adequate sensitivity. These values, however, may be affected by the separation conditions (e.g., column, reagents, instrumentation and data systems), necessary changes (e.g., pumping systems and detectors) and use of non-HPLC grade solvents and may result in changes in signal to noise ratios. 


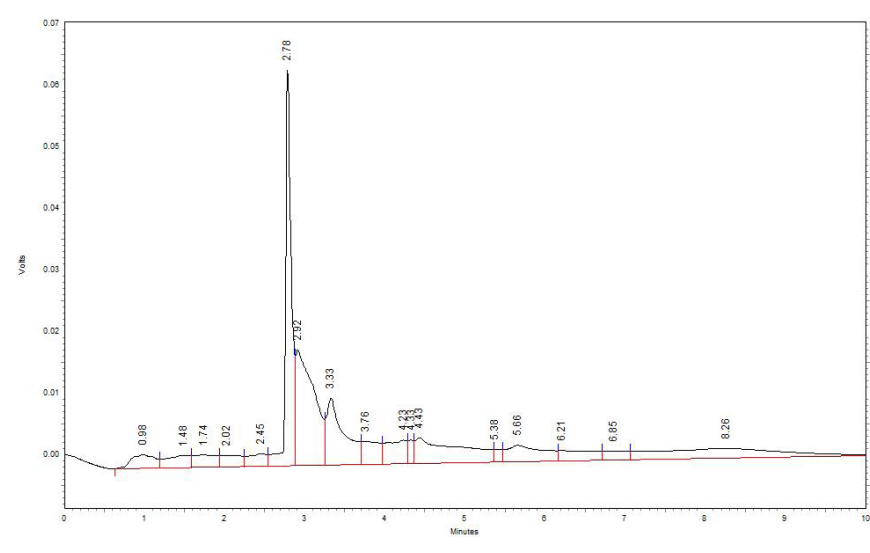

Figure 7: Chromatogram of Blank Rabbit Plasma.

Table 5: System Suitability Parameters.

\begin{tabular}{cc}
\hline Parameters & Menaquinone-4 \\
\hline Linearity and Range & $0.374-6 \mu \mathrm{g} / \mathrm{mL}$ \\
Regression Equation & $0.4221 \mathrm{x}-0.1091$ \\
Correlation Coefficient & 0.993 \\
Theoretical Plates & $7226 / \mathrm{m}$ \\
Asymmetric factor & 1.2 \\
Tailing factor & 1.2 \\
Limit of Detection (LOD) & $0.187 \mu \mathrm{g} / \mathrm{mL}$ \\
Limit of Quantification (LOQ) & $0.85 \mu \mathrm{g} / \mathrm{mL}$ \\
Resolution & $2.5 \mathrm{~min}$ \\
\hline
\end{tabular}

\section{Ruggedness and robustness}

The ruggedness and robustness of the methods were studied by changing the experimental conditions. No significant changes in the chromatographic parameters were observed when changing the experimental conditions (Operators, the source of reagents and column of similar type) and optimized conditions ( $\mathrm{pH}$, mobile phase ratio and flow rate).

\section{System suitability}

The System suitability parameters such as column efficiency (Theoretical plates), resolution factor of the optimized methods were found satisfactory and the output is shown in Table 5.

In conclusion, the developed method for the estimation of menaquinone- 4 in rabbit plasma was rapid, sensitive, precise, selective, linear and is, therefore, can be employed for a bioequivalence study to evaluate its applicability further.

\section{DISCUSSION}

A simple, cost-effective, accurate and fast HPLC method is vital for the routine measurement of menaquinone- 4 in plasma and to further study their pharmacokinetics in animal models. This is to correlate their pharmacological effects to plasma levels and pharmacokinetic behavior. In this article, we demonstrate a novel and simple UFLC-DAD method for the quantification of menaquinone- 4 in plasma of albino rabbits. To the best of our knowledge, so far, this is the first validated method that offers a simple and fast quantification for menaquinone- 4 in rabbit plasma. Optimizing chromatographic conditions was performed using different stationary phases, varying isopropyl alcohol, methanol and acetonitrile compositions and different flow rates. These methods failed to produce

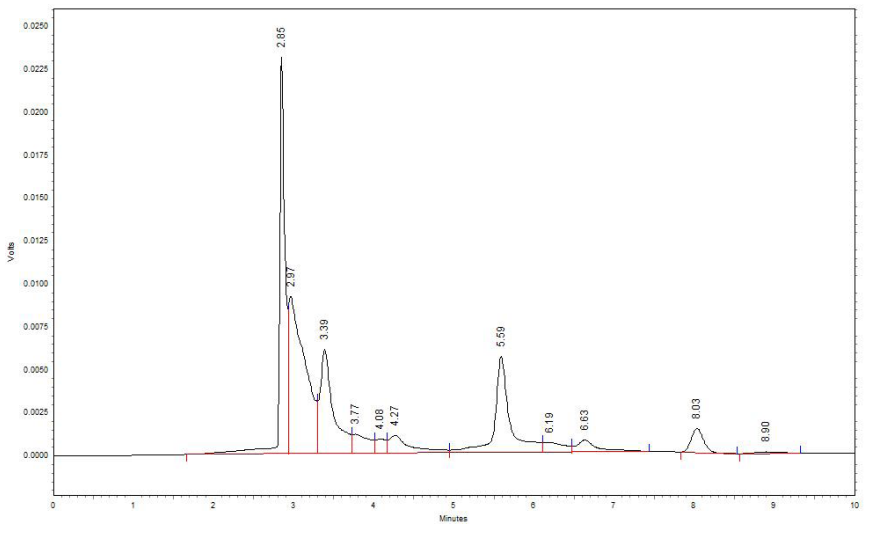

Figure 8: Chromatogram of Menaquinone-4 and IS Spiked in Rabbit Plasma.

symmetric peaks and peaks without optimal resolution suitable for quantification in plasma.

Data on the dietary admission of menaquinones is constrained because of the absence of diet tables that rundown menaquinone-4 fixation in ordinary nourishment. The quantitative analyses of menaquinone- 4 till date were done using HPLC-Fluorescence, ${ }^{11-16}$ HPLC-PDA, ${ }^{17-19}$ HPLC$\mathrm{MS}^{18,20}$ and HPLC-MS/MS ${ }^{17,21-24}$ techniques. Fluorescence detection for menaquinone-4 was carried in human serum,,${ }^{11,14,15}$ food, ${ }^{12}$ nutraceuticals $^{13}$ and human plasma ${ }^{16}$ for which a post-column reduction with zinc or zinc added to mobile phase has been used. There is no specified pathway mentioned for post-column derivatization and a comparison of fluorescence detection with other HPLC detections. Retention times of more than 10 mins were observed using HPLC-PDA detection. ${ }^{17,19,22,24}$ Mass detection was carried out for samples like human milk, ${ }^{17}$ plant extracts, ${ }^{18}$ feces, ${ }^{20}$ human serum, ${ }^{20,22}$ cell line,${ }^{21}$ human plasma, ${ }^{22}$ human osteoblasts ${ }^{23}$ and animal milk ${ }^{24}$ with menaquinone retention times of $9.8^{18}$ to $30.69^{19}$ mins, which is considered as a disadvantage concerned with the hyphenation. In conclusion, the developed method for the estimation of menaquinone- 4 in rabbit plasma is rapid, sensitive, precise, selective and linear and is, therefore, can be employed for a bioequivalence study to evaluate its applicability further.

\section{CONCLUSION}

A precise, validated bioanalytical method for the pharmacokinetic evaluation of Menaquinone- 4 was developed and validated. Menaquinone- 4 was eluted at 5.5 mins, which is an advantage as no other HPLC method has separated this compound below a retention time of 10 mins. This method also consumes less solvent when compared to other HPLC methods as menaquinones- 4 is usually separated using nonpolar solvents.

Till date, there were no pharmacokinetic studies of menaquinones- 4 in rabbits were reported. This method can be applied for the pharmacokinetic study of menaquinones- 4 in rabbits and can be further extended to human trials.

\section{CONFLICT OF INTEREST}

The authors declare no conflict of interest.

\section{ABBREVIATIONS}

$\boldsymbol{R}^{2}$ : Coefficient of regression; RSD: Relative standard deviation; SD: Standard deviation; MK-4: Menaquinone-4; MK-7: Menaquinone-7; MK-8: Menaquinone-8; MK-9: Menaquinone-9; MK-10: Menaquinone-10; IS: Internal standard; Gla: gamma-carboxy glutamate; OC: Osteocalcin; MGP: Matrix Gla Protein; QCs: Quality control samples; HQC: High 
quality control; MQC: Middle quality control; LQC: Low quality control; UV: Ultra violet.

\section{REFERENCES}

1. Cockayne S, Adamson J, Lanham-New S, Shearer MJ, Gilbody S, Torgerson DJ. Vitamin K and the prevention of fractures: systematic review and meta-analysis of randomized controlled trials. Arch Intern Med. 2006;166(12):1256-61.

2. Beulens JW, Bots ML, Atsma F, Bartelink ML, Prokop M, Geleijnse JM, et al. High dietary menaquinone intake is associated with reduced coronary calcification. Atherosclerosis. 2009;203(2):489-93.

3. Geleijnse JM, Vermeer C, Grobbee DE, Schurgers LJ, Knapen MH, DerMeer IMV, et al. Dietary intake of menaquinone is associated with a reduced risk of coronary heart disease: The Rotterdam Study. J Nutr. 2004;134(1):3100-5.

4. Spronk HM, Soute BA, Schurgers LJ, Thijssen HH, DeMey JG, Vermeer C. Tissue specific utilization of menaquinone-4 results in the prevention of arterial calcification in warfarin-treated rats. J Vasc Res. 2003;40(6):531-7.

5. Collins MD, Jones D. Distribution of isoprenoid quinone structural types in bacteria and their taxonomic implication. Microbiological Reviews. 1981;45(2):31654.

6. Booth SL, Suttie JW. Dietary intake and adequacy of vitamin K. J Nutr. 1998; 128(5):785-8

7. Thijssen $\mathrm{HH}$, Vervoort LM, Schurgers LJ, Shearer M. Menadione is a metabolite of oral vitamin K. Br J Nutr. 2006;95(2):260-6.

8. Schurgers LJ, Teunissen KJ, Hamulyak K, Knapen MH, Vik H, Vermeer C. Vitamin K-containing dietary supplements: comparison of synthetic vitamin $\mathrm{K}_{1}$ and natto-derived menaquinone-7. Blood. 2007;109(8):3279-83.

9. Rishavy MA, Berkner KL. Vitamin K oxygenation, glutamate carboxylation and processivity: defining the three critical facets of catalysis by the vitamin K-dependent carboxylase. Adv Nutr. 2012;3(2):135-48.

10. McCann JC, Ames BN. Vitamin K, an example of triage theory: Is micronutrient inadequacy linked to diseases of aging?. Am J Clin Nutr. 2009;90(4):889-907.

11. Toshiro S, Leon JS, Kazuhiro U. Comparision of menaquinone-4 and menaquinone-7 bioavailability in healthy women. Nutr J. 2012;11(93):1-4.

12. Koivo-Tikkanen TJ, Ollilainen V, Piironen VI. Determination of Phylloquinone and Menaquinones in Animal Products with fluorescence Detection after Post column Reduction with Metallic Zinc. J Agric Food Chem. 2000;48(12):6325-31.

13. Karuppiah SP, Anver BK. Vitamin K2-4 and K2-7 Estimation in Nutraceutical Solid Dosage forms by Post column Derivatization with fluorescence Detection. Indian J Pharm Sci. 2016;78(4):479-85.
14. Milka M, Dieter L, Philipp W, Matthias W, Olof B, Johannes O. A Validated HPLC Method for the Determination of Vitamin K in Human Serum-First Application in a Pharmacological Study. The Open Clinical Chemistry Journal. 2011;4:17-27.

15. Kalapkova E, Cepova J, Dunovska K, Prusa R. Determination of vitamins $K_{1}$, MK-4 and MK-7 in human serum of postmenopausal women by HPLC with fluorescence detection. J Clin Lab Anal. 2018;32(5):e22381.

16. Amemiya $T$, Mizuno $S$, Hayashi $Y$, Yuasa H, Watanabe J. Absorption of Vitamin $\mathrm{K}_{2}$ by Dogs after Oral Administration of a Soft Gelatin Capsule Formulation Containing a New Emulsion-type Vehicle. J Pharm Pharmacol. 1999;51(12):1375-80.

17. Gentili A, Caretti F, Bellante S, Ventura S, Canepari S, Curini R. Comprehensive Profiling of Carotenoids and Fat-Soluble Vitamins in Milk from Different Animal Species by LC-DAD-MS/MS Hyphenation. J Agric Food Chem. 2013;61 (8):162839.

18. Vinas P, Bravo-Bravo M, Lopez-Garcia I, Hernandez-Cordoba M. Dispersive liquid-liquid microextraction for the determination of vitamins $D$ and $K$ in foods by liquid chromatography with diode-array and atmospheric pressure chemical ionization-mass spectrometry detection. Talanta. 2013;115:806-13.

19. Borivoj K, Jitka P, David P, Vojtech A. Simultaneous determination of water and fat soluble vitamins in pharmaceutical preparations by HPLC-DAD. Anal Chim Acta. 2004:520(1):57-67.

20. Karl JP, Fu X, Dolnikowski GG, Saltzman E, Booth SL. Quantification of phylloquinone and menaquinones in feces, serum and, food by high performance liquid chromatography-mass spectrometry. J Chromatogr B Analyt Technol Biomed Life Sci. 2014;963:128-33.

21. Suhara $Y$, Wada $A$, Tachibana $Y$, Watanabe $M$, Nakamuta $K$, Nakagawa $K$, et al. Structure-activity relationships in the conversion of vitamin $K$ analogues into menaquinone-4. Substrates essential to the synthesis of menaquinone-4 in cultured human cell lines. Bioorg Med Chem. 2010;18(9):3116-24.

22. Gentili A, Cafolla A, Gasperi T, Bellante S, Caretti F Curini R, et al. Rapid, high performance method for the determination of vitamin $K_{1}$, menaquine- 4 and vitamin $K_{1}$ 2,3-epoxide in human serum and plasma using liquid chromatography-hybrid quadrupole linear ion trap mass spectrometry. J Chromatogr A. 2014;1338:102-10

23. Yoshihisa S, Kiyomi K, Kyoichi T, Kazuko H, Yasuko K. Simultaneous Determination of Menaquinone-4 and Its Metabolite in Human Osteoblasts by HPLCAPCl-MS/MS. Anal Sci. 1997;13(1):67-73.

24. Alessandra G, Alfredo M, Pierpaolo T, Mari EB, Roberta C, Perez-Fernandez V. Liquid chromatography-tandem mass spectrometry method for the determination of vitamin $\mathrm{K}$ homologues in human milk after overnight cold saponification. J Food Compost Anal. 2016;47:21-30.

Article History: Submission Date : 04-12-2018; Revised Date : 21-02-2019; Acceptance Date : 01-03-2019.

Cite this article: Anoop K, Kowmudi G, Sailaja M, Nagappan KV, Krishna NJS, Peraman R. An UFLC-DAD Method for the Quantification of Menaquinone-4 in Spiked Rabbit Plasma. J Young Pharm. 2019;11(2):149-54. 